\title{
Who dies and who survives? Investigating the difference between suicide decedents and suicide attempters
}

\author{
Suchita Rawat ${ }^{1}$, Sunanda Rajkumari ${ }^{1}$, Pooran Chand Joshi ${ }^{1}$, Maroof Ahmad Khan ${ }^{2}$ and Kallur Nava Saraswathy ${ }^{1 *}$
}

\begin{abstract}
Background: In spite of mounting evidence, it is still unclear whether suicide decedents and attempters represent overlapping or completely different populations of suicidal behavior subphenotypes. Hence, the present study aims to investigate the sociodemographic and suicidal behavior variables and the difference between suicide decedents and suicide attempters.

Methods: One hundred fifty suicide attempters and key informants of 206 suicide decedents were interviewed for sociodemographic and suicidal behavior characteristics using a semi-structured interview schedule. The statistical analysis was performed in SPSS ver. 20.

Results: The sociodemographic and suicidal behavior variables that distinguish suicide and suicide attempt in the multivariate logistics model were higher age $(\mathrm{OR}, 95 \% \mathrm{Cl}=1.06,1.032-1.09, p<0.001)$, male gender $(\mathrm{OR}, 95 \% \mathrm{Cl}=2.46$, $1.39-4.34, p=0.002)$, low socioeconomic status ( $\mathrm{OR}, 95 \% \mathrm{Cl}=0.94,0.90-0.98, p=0.005)$, occurrence in autumn season $(\mathrm{OR}, 95 \% \mathrm{Cl}=2.53,1.16-5.50, p=0.019)$, and usage of violent suicide method ( $\mathrm{OR}, 95 \% \mathrm{Cl}=17.82,7.33-43.32, p<0.001)$.

Conclusion: Suicide decedents were more likely to be older males, economically weaker, and commit suicide in an autumn season using violent suicide method. These findings emphasize the significance of distinct suicide prevention strategies for suicide decedents and suicide attempters.
\end{abstract}

Keywords: Suicide decedent, Suicide attempter, Male sex, Season, Socioeconomic status, Violent method

\section{Background}

Suicide is the 15th leading cause of death contributing to the premature death of almost one million individuals each year (World Health Organization 2014). It causes over 50 billion USD medical and work loss cost (Florence et al. 2015). A recent meta-analysis illustrated a 16 -fold increase in the risk of suicide among individuals with a previous suicide attempt (Yoshimasu et al. 2008). However, a previous literature hints that suicide decedents and suicide attempters belong to two distinct yet overlapping populations as only $10 \%$ of suicide attempters end their lives by suicide (Runeson et al. 2010) while 60\% of suicide decedents are devoid of previous suicide attempt (DeJong et al. 2010). Research studies evaluating the difference between suicide and suicide attempt are limited

\footnotetext{
* Correspondence: knsaraswathy@yahoo.com

'Department of Anthropology, University Of Delhi, Delhi 110007, India

Full list of author information is available at the end of the article
}

to WHO American region (DeJong et al. 2010), WHO Western Pacific region (Fushimi et al. 2006; Zhang et al. 2015; Liu et al. 2016), and WHO European region (Giner et al. 2013; Uribe et al. 2013; Younes et al. 2015; Pompili et al. 2016) while there is a dearth of studies in the WHO Southeast Asian region which contributes 60\% of worldwide suicide burden (Chen et al. 2011). Some cross-cultural variation in suicidal behavior exists between India and western countries in the domains of method of suicide such as agrochemicals usage; the presence of additional stressors, for instance, poverty, unemployment, domestic violence, and different vulnerable age groups such as married women reported among Indian populations.

Over the past three decades (1990-2016), India's contribution to global suicide deaths has increased from 25.3 to $36.6 \%$ for women and 18.7 to $24.3 \%$ for men (Dandona et al. 2018). In Telangana state, the DALY (disability-adjusted life year) attributed to self-harm has 
increased from $2.6 \%$ in 1990 to $3.5 \%$ in 2016 (Telangana disease burden profile 1990 to 2016, n.d.). In the Indian context, there is a paucity of studies probing the difference between suicide attempters and suicide decedents. There is only one study reported from Kerala (Kumar 2004). In consideration of this, the present study aims to investigate the possible difference in sociodemographic and suicidal behavior characteristics between suicide decedents and suicide attempters in a rural population of Telangana.

\section{Methods}

\section{Case identification}

The data for the present study was part of a major government-funded project. The study protocol was approved by the departmental ethical committee. All the study participants provided informed written consent. The study comprised of 206 suicide decedents (66 females and 140 males) and 150 suicide attempters (81 females and 69 males). Suicide decedents and suicide attempters were identified from Mahatma Gandhi Memorial Hospital Warangal, Telangana, with due permission from competent authority. Suicide was defined as the act of deliberately killing oneself (World Health Organization 2014). Suicide attempt was defined as self-inflicted, potentially injurious behavior with the non-fatal outcome for which there is evidence (implicit or explicit) of intent to die (Silverman et al. 2007).

\section{Data collection}

Based on the secondary data provided by the hospital, 35 villages with a high proportion of suicidal cases and located up to $40 \mathrm{~km}$ from Warangal city were selected for conducting fieldwork. Before conducting fieldwork in the villages, the local village head (sarpanch) or representative of the municipal corporation (for census town) were met to confirm the suicide death and obtain additional suicide cases not reported to MGM Hospital. Further, their help was sought for household identification of the cases and rapport establishment with study participants. The key informant of suicide decedents comprised of spouse (28.8\%), parents (19.4\%), children (15.5\%), siblings (10.2\%), grandparents $(2.9 \%)$, other blood relatives $(9.7 \%)$, in-laws (13.1\%), and neighborhood friends $(4.4 \%)$. The key informants were contacted minimum 2 months after bereavement period.

The semi-structured interview was tested and modified during a pilot survey conducted in September 2016. The fieldwork of the present study was conducted over the tenure of 5 months. The data was collected by Ph.D. research scholars who were extensively trained prior to fieldwork. Since the fieldwork was in Telangana, an interpreter assisted the researchers during fieldwork for local language assistance. The refusal rate was $9.4 \%$ for suicide decedents and $9.1 \%$ for suicide attempters.

\section{Sociodemographic variables}

Suicide attempters and key informants of suicide decedents were interviewed for $30-45 \mathrm{~min}$ face to face to collect data on sociodemographic and characteristics of suicidal behavior, similar to the methodology used in the previous studies by DeJong et al. 2010 and Giner et al. 2013. The semi-structured interview schedule comprised of sociodemographic variables such as age, sex, caste, religious affiliation, marital status, family type, education, occupation, tobacco usage, or alcohol consumption. The semi sturctured interview was adapted from NCRB proforma (NCRB 2017). The socioeconomic status was measured using the Udai Pareek socioeconomic scale used for rural populations in India (Raj et al. 2015).

\section{Suicidal behavior characteristics}

The suicidal behavior characteristics comprised of the season, the method employed, family history of suicidal behavior, self-history of the previous attempt, alcohol intoxication during suicidal act, and reason for the suicidal act. In the present study, the method of suicide was bifurcated into either violent method (such as self-immolation, drowning, hanging, sharp self-inflicted injury, getting run over by moving vehicle) or non-violent method (such as poisoning) (Asberg et al. 1976).

The suicide cause was classified into four categories: (1) economic cause comprising of reasons such as bankruptcy or indebtedness due to crop loan or farm equipment loan or nonagricultural loan, failure of crop, poverty, career or professional problems, and unemployment; (2) health-related cause comprising of reasons such as alcohol addiction or prolonged illness; (3) marriage-related cause comprising of reasons such as non-settlement of marriage, extramarital affairs, or dowry-related issues; and (4) personal or social-related cause comprising of reasons such as family problems, property dispute, love affair, death of dear person, failure in examination, impotency or infertility, ideological issues/hero worship, and fall in social reputation (Dandona et al. 2016) In the present study, 3.3\% of the suicide attempters did not share the cause of their suicide attempt while $9.7 \%$ of the key informants of suicide decedents were unaware of the reason for suicide.

\section{Statistical analysis}

In the present study, data analysis was performed in SPSS version 20 (IBM-SPSS Inc. Chicago, IL). In the present study, univariate analysis using binary logistics to compute relative risk of sociodemographic and suicide-related characteristics for suicide in comparison to suicide attempt was performed. Further multivariate backward stepwise regression was performed comprising of variables significant in univariate analysis. The predictors variables included in the multivariate backward 
stepwise regression were age, sex (female as reference), caste (forward caste as reference), religious affiliation (minority as reference), occupation(employed as reference), Udai Pareek socioeconomic score, alcohol consumption (no alcohol consumption as reference), season (winter as reference), method employed (nonviolent as reference), previous suicide attempt (no history as reference), and reason for suicidal act, i.e., economic, health, marriage, or personal/social (one group at risk while the other three groups as reference). All the statistical tests were considered significant at two tailed $p<0.05$.

\section{Results}

\section{Baseline characteristics of study groups}

The suicide decedents group consisted of $68 \%$ males and $32 \%$ of females who died in the fourth decade of life. The majority of them belonged to a backward caste group (66.5\%), religiously affiliated as Hindus (81.1\%), married (75.7\%), cohabitated in a nuclear family (67.5\%), educated (70.4\%), and employed (81.1\%\%). The suicide occurred predominantly in summer or autumn (28.6\%) seasons. The method used for suicide were nonviolent (60.2\% agrochemical poisoning, 10.2\% non-agrochemical poisoning) and violent (18.9\% self-immolation, $6.3 \%$ hanging, $1.5 \%$ drowning, $2.4 \%$ coming under moving the train, and $0.5 \%$ self-inflicted sharp injury). The majority of the suicides occurred due to economic distress (41.7\%) (Table 1).

The suicide attempters group comprised of $46 \%$ males and $54 \%$ of females who attempted suicide at the third decade of life. The majority of them belonged to a scheduled caste $(50 \%)$, affiliated as Hindus (66\%), married (82\%), cohabited in a nuclear family (68.7\%), educated (77.9\%), and employed (74.0\%). The majority of the suicide attempts occurred in the winter season (29.3\%). The methods of suicide attempt were nonviolent $(45.3 \%$ agrochemical poisoning, $24 \%$ non-agrochemical poisoning, $16 \%$ multiple tablets overdoses, $9.3 \%$ hair dye, i.e., supervasmol) or violent ( $2 \%$ self-immolation, $2 \%$ hanging, and $0.7 \%$ drowning). The most common trigger for suicide attempts was a personal/social-related issue (41.3\%) (Table 1).

\section{Univariate and multivariate analysis}

Univariate analysis illustrated that in comparison to suicide attempters, the suicide decedents were more likely to be older, males, Hindus, economically weaker, and alcohol consumers. Further, suicide was more likely occurred in the autumn season due to economic or health-related issues. However, in comparison to suicide attempters, suicide decedents were less likely to be from a scheduled caste and less likely to have a previous suicide attempt (Table 1).
Multivariate backward stepwise regression comprising of variables significant in univariate analysis illustrated that the relative risk of suicide in comparison to suicide attempt was associated with sociodemographic variables such as age (OR, 95\%CI 1.06, 1.03-1.09, $p<0.001)$, male sex (OR, 95\%CI 2.46, 1.39-4.34, $p=0.002)$, and suicidal behavior variables such as autumn season (OR, 95\%CI $2.53,1.16-5.50, p=0.019$ ) and violent method (OR, 95\%CI 17.82, 7.33-43.32, $p<0.001)$. Further, socioeconomic status (OR, 95\%CI 0.94, 0.90-0.98, $p=0.005$ ) and marital reason for suicidal act (OR, 95\%CI $0.42,0.22-0.78$, $p=0.007$ ) were negatively associated (Table 1 ).

\section{Discussion}

In consensus with the gender paradox of suicidal behavior, a higher rate of male suicide while female suicide attempts were observed in the present study. Similar observations were also reported in previous epidemiological studies (Liu et al. 2016), hospital-based inpatients studies (DeJong et al. 2010; Zhang et al. 2015), and retrospective hospital record investigation of the difference between suicide attempters and decedents (Uribe et al. 2013; Joo et al. 2016). The high rate of male suicide than female suicide could possibly be attributed to the disparity in socially accepted coping methods for dealing with stress and difference in care-seeking behavior (Hamilton and Klimes-Dougan 2015). Women are more socially integrated with family and friends compared to men which guarantees support in difficult times while men are also exposed to cultural pressures to conceal feelings of weakness and vulnerability. Further. the higher rate of male suicide could be due to the higher suicide intent and exacerbated suicidal tendency under the influence of alcohol (Mergl et al. 2016). In the present cohort, suicide decedents died in the fourth decade of life (30-40 years) while the majority of suicide attempt occurred in the third decade of life (20-30 years), indicating a distinct vulnerable age for the suicide and suicide attempt.

Religion plays an important role in a person's life and is also expected to influence suicidal behavior. Religious belief or religious prohibition against suicide deters a person from ending his life in a personal crisis. Further, the religious network provides social support and strong interpersonal relationships which lower suicide risk. Studies in this field have reported that religiosity measured by religious service attendance or self-reported religiosity is a protective factor for suicide, self-injurious thoughts, and behavior (Amit et al. 2014). In the present study, the proportion of suicide decedents was higher among the Hindus while suicide attempters were more likely to be Christians. Suicide is not accepted in Christianity and is displayed in the sixth Commandment "Thou Shall does not kill", a Christian statement to prohibit suicide 
Table 1 Comparison of sociodemographic variables and suicide behavior characteristics

\begin{tabular}{|c|c|c|c|c|}
\hline Variables & $\begin{array}{l}\text { Suicide attempter; } \\
N=150\end{array}$ & $\begin{array}{l}\text { Suicide victim; } \\
N=206\end{array}$ & $\begin{array}{l}\text { Univariate; } \mathrm{OR}(95 \% \mathrm{Cl}) \text {, } \\
p \text { value }\end{array}$ & $\begin{array}{l}\text { Multivariate; OR }(95 \% \mathrm{Cl}) \text {, } \\
p \text { value }\end{array}$ \\
\hline Age in years (mean $\pm S D$ ) & $28.81 \pm 7.88$ & $36.72 \pm 14.72$ & $1.06(1.04-1.08), p<0.001^{* *}$ & $1.06(1.03-1.09), p<0.001^{* *}$ \\
\hline \multicolumn{5}{|l|}{ Sex } \\
\hline Female & $81(54 \%)$ & $66(32 \%)$ & Reference & Reference \\
\hline Male & $69(46 \%)$ & $140(68 \%)$ & $2.49(1.61-3.84), p<0.001^{* *}$ & $2.46(1.39-4.34), p=0.002^{*}$ \\
\hline Caste & & & & - \\
\hline Forward caste & $6(4.0 \%)$ & $9(4.4 \%)$ & Reference & \\
\hline Backward caste & $69(46.0 \%)$ & $137(66.5 \%)$ & $0.76(0.26-2.22), p=0.618$ & \\
\hline Scheduled caste & $75(50.0 \%)$ & $53(25.7 \%)$ & $0.36(0.23-0.58), p<0.001^{* *}$ & \\
\hline Schedule tribe & $0(0 \%)$ & $7(3.4 \%)$ & - & \\
\hline Religious affiliation & & & & - \\
\hline Minority (Muslim and Christian) & $51(34.0 \%)$ & 39 (18.9\%) & Reference & \\
\hline Hindu & $99(66.0 \%)$ & $167(81.1 \%)$ & $2.20(1.36-3.58), p=0.001^{*}$ & \\
\hline \multicolumn{5}{|l|}{ Marital status } \\
\hline Married & $123(82.0 \%)$ & $156(75.7 \%)$ & Reference & \\
\hline Never married or widow or separated & $27(18.0 \%)$ & $50(24.3 \%)$ & $1.46(0.86-2.47), p=0.196$ & \\
\hline \multicolumn{5}{|l|}{ Family type } \\
\hline Joint & $47(31.3 \%)$ & $67(32.5 \%)$ & Reference & \\
\hline Nuclear & $103(68.7 \%)$ & $139(67.5 \%)$ & $0.95(0.60-1.49), p=0.819$ & \\
\hline \multicolumn{5}{|l|}{ Education status } \\
\hline Educated & $116(77.9 \%)$ & $145(70.4 \%)$ & Reference & \\
\hline Uneducated & $33(22.1 \%)$ & $61(29.6 \%)$ & $1.48(0.91-2.41), p=0.143$ & \\
\hline \multicolumn{5}{|l|}{ Occupation $^{a}$} \\
\hline Employed & $111(74.0 \%)$ & $167(81.1 \%)$ & Reference & \\
\hline Unemployed & $39(26.0 \%)$ & $39(18.9 \%)$ & $0.66(0.40-1.10), p=0.113$ & \\
\hline Socioeconomic score $($ mean \pm SD) & $26.32 \pm 6.27$ & $24.51 \pm 7.68$ & $0.96(0.94-1.00), p=0.022^{*}$ & $0.94(0.90-0.98), p=0.005^{*}$ \\
\hline \multicolumn{5}{|l|}{ Alcohol consumption } \\
\hline No & $118(78.7 \%)$ & $126(61.2 \%)$ & Reference & - \\
\hline Yes & $32(21.3 \%)$ & $80(38.8 \%)$ & $2.34(1.45-3.79), p=0.001^{*}$ & \\
\hline \multicolumn{5}{|l|}{ Tobacco usage } \\
\hline No & $120(80.0 \%)$ & $159(77.2 \%)$ & Reference & \\
\hline Yes & $30(20.0 \%)$ & $47(22.8 \%)$ & $1.18(0.71-1.98), p=0.602$ & \\
\hline \multicolumn{5}{|l|}{ Family history suicidal behavior } \\
\hline No & $101(67.3 \%)$ & $153(74.3 \%)$ & Reference & \\
\hline Yes & 49 (32.7\%) & $53(25.7 \%)$ & $0.71(0.45-1.13), p=0.157$ & \\
\hline Previous suicide attempt & & & & - \\
\hline No & $128(85.3 \%)$ & $191(92.7 \%)$ & Reference & \\
\hline Yes & $22(14.7 \%)$ & $15(7.3 \%)$ & $0.48(0.24-0.97), p=0.049^{*}$ & \\
\hline \multicolumn{5}{|l|}{ Alcohol intoxication during the suicidal act } \\
\hline No & $122(81.3 \%)$ & $159(77.2 \%)$ & Reference & \\
\hline Yes & $28(18.7 \%)$ & $47(22.8 \%)$ & $1.29(0.76-2.18), p=0.360$ & \\
\hline \multicolumn{5}{|l|}{ Season } \\
\hline Winter & $43(29.3 \%)$ & $42(20.4 \%)$ & Reference & Reference \\
\hline Spring & $42(28.6 \%)$ & $46(22.3 \%)$ & $1.12(0.62-2.04), p=0.707$ & $0.78(0.36-1.67), p=0.516$ \\
\hline
\end{tabular}


Table 1 Comparison of sociodemographic variables and suicide behavior characteristics (Continued)

\begin{tabular}{|c|c|c|c|c|}
\hline Variables & $\begin{array}{l}\text { Suicide attempter; } \\
N=150\end{array}$ & $\begin{array}{l}\text { Suicide victim; } \\
N=206\end{array}$ & $\begin{array}{l}\text { Univariate; } \mathrm{OR}(95 \% \mathrm{Cl}) \text {, } \\
p \text { value }\end{array}$ & $\begin{array}{l}\text { Multivariate; } \mathrm{OR}(95 \% \mathrm{Cl}), \\
p \text { value }\end{array}$ \\
\hline Summer & $38(25.9 \%)$ & $59(28.6 \%)$ & $1.59(0.88-2.86), p=0.123$ & $0.94(0.44-2.00), p=0.870$ \\
\hline Autumn & $24(16.3 \%)$ & $59(28.6 \%)$ & $2.52(1.33-4.76), p=0.005^{*}$ & $2.53(1.16-5.50), p=0.019^{*}$ \\
\hline \multicolumn{5}{|c|}{ Method employed ${ }^{b}$} \\
\hline Violent & $8(5.3 \%)$ & $61(29.6 \%)$ & $7.47(3.45-16.17), p<0.001^{* *}$ & $17.82(7.33-43.32), p<0.001^{* *}$ \\
\hline Non-violent & $142(94.7 \%)$ & $145(70.4 \%)$ & Reference & Reference \\
\hline \multicolumn{5}{|c|}{ Reason for the suicidal act } \\
\hline Economic & $38(25.3 \%)$ & $86(41.7 \%)$ & $2.11(1.33-3.35), p=0.001^{*}$ & - \\
\hline Health & $14(9.3 \%)$ & $36(17.5 \%)$ & $2.06(1.066-3.97), p=0.031^{*}$ & - \\
\hline Marriage & $51(34.0 \%)$ & 41 (19.9\%) & $0.48(0.298-0.78), p=0.003^{*}$ & $0.42(0.22-0.78), p=0.007^{*}$ \\
\hline Personal/social & $62(41.3 \%)$ & $61(29.6 \%)$ & $0.60(0.384-0.93), p=0.022^{*}$ & - \\
\hline
\end{tabular}

*Significant at the 0.05 level (two-tailed)

**Significant at the 0.01 level (two-tailed)

aEmployed: salaried employee, agricultural labors, farmers, and self-employed; unemployed: housewives, students, and unemployed

${ }^{b}$ Non-violent method: poisoning; violent method: hanging, self-immolation, drowning, self-inflicted sharp injury, and coming under moving a train

(Sisask et al. 2010). Hindu religious opposition towards suicide is evident from the negative outlook about suicide in Hindi mythological books such as Manu-Smriti, Yama-Smriti, Garuda Purana, and Arthasastra though occasional approval to suicide is seen in the case of Sati and Samadhi-Marana (Agoramoorthy and Hsu 2017). However, the role in religion as a protective or deterrent factor falls beyond the preview of the present paper and needs further exploration.

The WHO World Mental Health Survey (WMH) conducted from 2001 to 2007 suggested low income as a predictor of suicidal behavior (Borges et al. 2010). In the present study, suicide decedents had lower socioeconomic status than suicide attempters which is similar to the observation of past studies (Zhang et al. 2015; Liu et al. 2016). Alcohol is an important risk factor for suicidal behavior due to elevated impulsiveness and aggressiveness after alcohol consumption (Darvishi et al. 2015). In the present study, suicide decedents had a higher proportion of alcohol consumers than suicide attempters; this observation is in accordance with previous literature (Giner et al. 2013; Uribe et al. 2013; Joo et al. 2016). Previous literature indicates higher rates of marital dissolution individuals, i.e., widowed, separated, lower educational qualification, and living alone among suicide decedents compared to suicide attempters (Yoshimasu et al. 2008; Zhang et al. 2015; Giner et al. 2013; Uribe et al. 2013); however, these differences were absent in the present groups indicating an overlap of these sociodemographic parameters.

In the domain of suicidal behavior characteristics, it was observed that suicide decedents employed a more violent method in comparison to suicide attempters and the same was also observed in previous studies (Zhang et al. 2015; Liu et al. 2016; Uribe et al. 2013;
Younes et al. 2015; Joo et al. 2016). This difference could be attributed due to the difference between suicide decedent and attempters in the realm of psychiatric diagnosis (Giner et al. 2013; Uribe et al. 2013), personality trait, i.e., impulsivity, hopelessness, and intense suicide ideation (Giner et al. 2013; Uribe et al. 2013; Younes et al. 2015; Joo et al. 2016; Liu et al. 2016), psychosocial parameters (Zhang et al. 2015; DeJong et al. 2010; Giner et al. 2013), and availability of suicide method (Zhang et al. 2015; Liu et al. 2016) as reported in past studies. Restriction of the violent method of suicide, psychological counseling, and rehabilitation of individuals with self-harm behavior could be initiated. Further seasonality of suicide, i.e., autumn peak, was observed decedents which are in consensus with previous studies (Coimbra et al. 2016); hence, screening of risk population and strengthening of current medical emergency interventions could be initiated around this hotspot time frame for self-harm patients. In the present study compared to suicide attempters, suicide decedents had less history of previous suicide attempt which coincides with the previous studies (DeJong et al. 2010; Younes et al. 2015; Joo et al. 2016), indicating that suicide decedents are successful in ending their lives in a single attempt due to either stronger intent or use of violent suicide method.

In the present study, economic distress was a trigger for suicide. This observation is in consensus with Indian studies (Manoranjitham et al. 2010) where the triggers for the suicide attempt were personal or social problems which have also been reported as Indian studies (Benjamin et al. 2018). Hence, for suicide decedents, the suicide prevention strategies could be invested in the betterment of economic status, while among suicide attempters, family counseling could be initiated. 
The limitations of the present study are non-assessment psychiatric disorders, personality traits, and suicide intent among suicide decedent which could be diagnosed by only a psychiatric or mental health professional. Further, the proxy-based interview technique for suicide decedents could create recall bias and undermine the true picture of some of the study variables. In the limited sample size, the analysis based on sex stratification was not possible. To our knowledge, the present study is the first study to investigate the possible difference between suicide decedents and suicide attempters of the same geographical area in India having an enormous burden of suicidal behavior.

\section{Conclusion}

The present study found the difference between suicide decedents and suicide attempters in few sociodemographic and suicidal behavior characteristics, so better characterization could be valuable in implementing distinctive preventive policies.

\section{Abbreviations}

DALY: Disability-adjusted life year; MGM: Mahatma Gandhi Memorial;

USD: United States dollar; WHO: World Health Organization

\section{Acknowledgements}

The authors are thankful to ICSSR (Indian Council for Social Science Research) financial assistance and the study participants for their kind cooperation.

\section{Funding}

The data used in the present study was part of ICSSR (Indian Council for Social Science Research) financial assistance of major funded project (F.No. 02/270/2016-17/RP; 1-06-2017).

\section{Availability of data and materials}

The data used and analyzed in this study are available from the corresponding author on reasonable request.

\section{Authors' contributions}

The study was conceptualized by KNS and SR. Primary data collection was done by SR and SR. The statistical analysis was performed and interpreted under the supervision of MAK. The manuscript was drafted by SR. All critical revision in the manuscript was done by KNS and PCJ. All authors read and approved the final manuscript.

\section{Authors' information}

Suchita Rawat and Sunanda Rajkumari are Ph.D. Research Scholar at Dept. Of Anthropology, University of Delhi. Prof. Pooran Chand Joshi is Professor, Dept. Of Anthropology, University of Delhi. Dr. Maroof Ahmad Khan is Associate Professor, Department of Biostatistics, All India Institute of Medical Sciences (AllMS) New Delhi. Dr. Kallur Nava Saraswathy is Assistant Professor, Dept of Anthropology, University of Delhi.

\section{Ethics approval and consent to participate}

This study was approved by the Ethical Committee of the Department of Anthropology, University of Delhi.

\section{Consent for publication}

Not applicable

\section{Competing interests}

The authors declare that they have no competing interests.

\section{Publisher's Note}

Springer Nature remains neutral with regard to jurisdictional claims in published maps and institutional affiliations.

\section{Author details}

${ }^{1}$ Department of Anthropology, University Of Delhi, Delhi 110007, India. 2Department of Biostatistics, All India Institute of Medical Sciences (AlIMS), New Delhi 110029, India.

Received: 26 December 2018 Accepted: 18 February 2019

Published online: 01 March 2019

\section{References}

Agoramoorthy G, Hsu MJ (2017) The suicide paradigm: insights from ancient Hindu scriptures. J Relig Health 56(3):807-816

Amit BH, Krivoy A, Mansbach-Kleinfeld I, Zalsman G, Ponizovsky AM, Hoshen M et al (2014) Religiosity is a protective factor against self-injurious thoughts and behaviors in Jewish adolescents: findings from a nationally representative survey. Eur Psychiatry 29(8):509-513

Asberg M, Traskman L, Thoren P (1976) 5-HIAA in the cerebrospinal fluid. A biochemical suicide predictor? Arch Gen Psychiatry 33:1193-1197

Benjamin RN, David T, lyadurai R, Jacob KS (2018) Suicidal nonorganophosphate poisoning in a tertiary hospital in South India: nature, prevalence, risk factors. Indian J Psychol Med 40(1):47.

Borges G, Nock MK, Abad JM, Hwang I, Sampson NA, Alonso J et al (2010) Twelve-month prevalence of and risk factors for suicide attempts in the WHO World Mental Health Surveys. J Clin Psychiatry 71(12):1617

Chen YY, Chien-Chang Wu K, Yousuf S, Yip PS (2011) Suicide in Asia: opportunities and challenges. Epidemiol Rev 34(1):129-144

Coimbra DG, e Silva AC, de Sousa-Rodrigues CF, Barbosa FT, de Siqueira Figueredo D, Santos JL et al (2016) Do suicide attempts occur more frequently in the spring too? A systematic review and rhythmic analysis. J Affect Disord 196:125-137

Dandona R, Bertozzi-Villa A, Kumar GA, Dandona L (2016) Lessons from a decade of suicide surveillance in India: who, why and how? Int J Epidemiol 46(3):983-993

Dandona R, Kumar GA, Dhaliwal RS, Naghavi M, Vos T, Shukla DK et al (2018) Gender differentials and state variations in suicide deaths in India: the Global Burden of Disease Study 1990-2016. Lancet Public Health 3(10):e478-e489

Darvishi N, Farhadi M, Haghtalab T, Poorolajal J (2015) Alcohol-related risk of suicidal ideation, suicide attempt, and completed suicide: a meta-analysis. PLoS One 10(5):e0126870

DeJong TM, Overholser JC, Stockmeier CA (2010) Apples to oranges? A direct comparison between suicide attempters and suicide completers. J Affect Disord 124(1-2):90-97

Florence C, Simon T, Haegerich T, Luo F, Zhou C (2015) Estimated lifetime medical and work-loss costs of fatal injuries_-United States, 2013. MMWR Morb Mortal Wkly Rep 64(38):1074-1077

Fushimi M, Sugawara J, Saito S (2006) Comparison of completed and attempted suicide in Akita, Japan. Eur Arch Psychiatry Clin Neurosci 60(3):289-295

Giner L, Blasco-Fontecilla H, Perez-Rodriguez MM, Garcia-Nieto R, Giner J, Guija JA (2013) Personality disorders and health problems distinguish suicide attempters from completers in a direct comparison. J Affect Disord 151(2):474-483

Hamilton E, Klimes-Dougan B (2015) Gender differences in suicide prevention responses: implications for adolescents based on an illustrative review of the literature. Int J Environ Res Public Health 12(3):2359-2372

Joo SH, Wang SM, Kim TW, Seo HJ, Jeong JH, Han JH (2016) Factors associated with suicide completion: a comparison between suicide attempters and completers. Asia Pac Psychiatry 8(1):80-86

Kumar PS (2004) An analysis of suicide attempters versus completers in Kerala. Indian J Psychiatry 46(2):144

Liu BP, Liu X, Jia CX (2016) Characteristics of suicide completers and attempters in rural Chinese population. Compr Psychiatry 70:134-140

Manoranjitham SD, Rajkumar AP, Thangadurai P, Prasad J, Jayakaran R, Jacob KS (2010) Risk factors for suicide in rural South India. Br J Psychiatry 196(1):26-30

Mergl R, Koburger N, Heinrichs K, Székely A, Tóth MD, Coyne J et al (2016) What are reasons for the large gender differences in the lethality of suicidal acts? An epidemiological analysis in four European countries. PLoS One 10(7):e0129062

National Crime Records Bureau of the Ministry of Home Affairs, Government of India, Report on Accidents and Suicides in India (2010-2015). 2017 http:// ncrb.gov.in/ Accessed 31 May 2017 
Pompili M, Innamorati M, Milelli M, Battuello M, Erbuto D, Lester D et al (2016) Temperaments in completed suicides: are they different from those in suicide attempters and controls? Compr Psychiatry 65:98-102

Raj G, Shilpa S, Maheshwaran R (2015) Revised socio-economic status scale for urban and rural India-revision for 2015. SJSECO 4(7):167-174

Runeson B, Tidemalm D, Dahlin M, Lichtenstein P, Långström N (2010) Method of attempted suicide as predictor of subsequent successful suicide: national long-term cohort study. BMJ 341:C3222

Silverman MM, Berman AL, Sanddal ND, O'carroll PW, Joiner TE Jr (2007) Rebuilding the tower of Babel: a revised nomenclature for the study of suicide and suicidal behaviors. Part 1: background, rationale, and methodology. Suicide Life Threat Behav 37(3):248-263

Sisask M, Värnik A, Bertolote JM, Bolhari J, Botega NJ, Fleischmann A (2010) Is religiosity a protective factor against attempted suicide: a cross-cultural casecontrol study. Arch Suicide Res 14(1):44-55

Telangana disease burden profile 1990 to 2016(n.d.) accessed from https://phfi. org/wp-content/uploads/2018/05/Telangana-Disease-Burden-Profile.pdf Assessed on 31 January 2019

Uribe IP, Blasco-Fontecilla H, Garcia-Pares G, Batalla MG, Capdevila ML, Meca AC (2013) Attempted and completed suicide: not what we expected? J Affect Disord 150(3):840-846

World Health Organization. Preventing suicide: A global imperative. 2014. https:// www.who.int/mental_health/suicide-prevention/world_report_2014/en/ Accessed 1 May 2017

Yoshimasu K, Kiyohara C, Miyashita K (2008) Suicidal risk factors and completed suicide: meta-analyses based on psychological autopsy studies. Environ Health Prev Med 13(5):243

Younes N, Melchior M, Turbelin C, Blanchon T, Hanslik T, Chee CC (2015) Attempted and completed suicide in primary care: not what we expected? J Affect Disord 170:150-154

Zhang J, Sun L, Conwell Y, Qin P, Jia CX, Xiao S, Tu XM (2015) Suicides and medically serious attempters are of the same population in Chinese rural young adults. J Affect Disord 176:176-182

\section{Submit your manuscript to a SpringerOpen ${ }^{\circ}$ journal and benefit from:}

- Convenient online submission

- Rigorous peer review

- Open access: articles freely available online

- High visibility within the field

- Retaining the copyright to your article

Submit your next manuscript at $\boldsymbol{\nabla}$ springeropen.com 